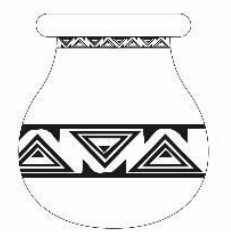

\title{
FILOSOFIA NO BRASIL: CONSIDERAÇÕES ACERCA DOS PERFIS INICIAIS DE UM ACONTECIMENTO
}

\author{
Roberto de Almeida Pereira de Barros ${ }^{1}$
}

Resumo: A chegada e o estabelecimento da reflexão filosófica europeia no Brasil são indissociáveis do aristotelismo português trazido pelos jesuítas desde sua chegada ao então território colonial em 1549. A compreensão de determinados aspectos relacionados a este acontecimento não deve implicar na proposição de um fator determinista para a interpretação do modo como a filosofia é multiplamente tratada e pesquisada no país, mas certamente consiste em um fator imprescindível para a sua consideração. A argumentação a seguir visa indicar alguns aspectos ainda presentes na forma segundo a qual a filosofia ainda é pensada entre nós.

Palavras-chave: Aristotelismo ; Jesuítas; Ratio Studiorum; Escolástica

Abstract: The arrival and establishment of European philosophical reflection in Brazil are inseparable from the Portuguese Aristotelianism brought by the Jesuits since their arrival in the Portuguese colonial territory in 1549. The understanding of certain aspects related to this event should not imply in the proposition of a deterministic factor for the interpretation of how philosophy is multiplied and researched in Brazil, but it certainly is an essential factor for its consideration. The following Argumentation is intended to indicate some aspects still present in the form according to which philosophy is still thought among us.

Key Words: Aristotelism; Jesuits; Ratio Studiorum; Scholastic.

\footnotetext{
${ }^{1}$ Professor da Faculdade de Filosofia (FAFIL) e do Programa de Pós-Graduação (PPGFIL) da Universidade Federal do Pará (UFPA). E-mail: robertbarr@gmx.net.
} 
Belém, 2019, V. 1, N.1.

\section{Introdução}

O processo de exploração dos territórios sob influência da política expansionista portuguesa na América do Sul possui dois componentes centrais: a superioridade tecnológica e a religião como meio de conversão dos habitantes originários. Enquanto nação que no século XVI não contava com mais de um milhão de habitantes (RODRIGUES, 2010, p. 24), era absolutamente impossível para a Coroa portuguesa cogitar a ocupação territorial das áreas sob seu domínio - que então se estendiam da Índia à América do Sul - sem a integração com os habitantes locais. O processo de conversão dos indígenas foi, então, inevitável para a ocupação e exploração do vasto território e ele foi decisivamente levado a cabo desde as primeiras décadas da colonização do Brasil. A expansão marina dos ibéricos foi marcada por um forte apelo salvacionista e pela evangelização (RIBEIRO, 1995, p. 65) e é neste contexto que a filosofia europeia alcança as terras brasileiras, prioritariamente por intermédio da ordem jesuíta, criada em 1534 na França para ser, com sua disciplina militar, uma força contrareformista decisiva da igreja católica. A sua Ascenção foi rápida, e em 1542 os jesuítas se estabeleciam definitivamente em Portugal, com a fundação da escola de Santo Antão, à qual viriam a se seguir várias outras, como a de Coimbra e o Colégio das Artes e que só chegaria ao fim com sua expulsão, em 1759, de Portugal e das colônias por ordem de Sebastião José de Carvalho e Melo, o Marquês de Pombal (1699-1782).

A educação jesuítica é o veículo de chegada, transmissão e estabelecimento do estudo de filosofia no Brasil, estando assim em consonância com a decisão papal de 1366, que tornara obrigatório o estudo de Aristóteles no ensino público de filosofia (CERQUEIRA, 2011, p. 164), constituindo-se, portanto, na matriz de dois aspectos nucleares da primeira recepção da filosofia européia no Brasil, o aristotelismo e o esforço escolástico de superar o conflito entre fé e razão em favor da primeira. Estes dois aspectos resultam na assimilação de um procedimento metodológico ferreamente assimilado pelo estudo filosófico no Brasil e que também requer a compreensão da influência jesuíta: a exegese do texto como princípio de validade objetiva do estudo filosófico. A argumentação a seguir busca analisar estes três aspectos, tendo em vista a apresentação de um quadro geral dos primórdios da recepção da filosofia no Brasil. 


\section{Expansão marítima portuguesa e a filosofia dos jesuítas}

A filosofia chega em terras brasileiras trazida pelos padres da Companhia de Jesus (Scocietas Jesus), o que estava relacionado com a expansão ibérica iniciada pelos portugueses. Fundada na França em 1534 e oficializada pelo Papa Paulo III em 1540 como força contrareformista, a Companhia de Jesus foi concebida como corpo missionário regido por severa disciplina militar, como pode ser percebido pelo título da bula papal (regimini militantis ecclesiae), antecedendo claramente o espírito do Concílio de Trento iniciado cinco anos depois (1545 - 1563), no qual a igreja católica buscava reforçar a fé cristã e a disciplina eclesiástica ante o avanço do protestantismo. Portugal foi a primeira Coroa a oferecer auxílio e serviços à Ordem, dando início a um processo de ascensão da significação política dos jesuítas por meio não apenas de seus serviços religiosos, mas também educacionais. Em dois séculos de participação ininterrupta na expansão portuguesa, os jesuítas criaram inúmeras escolas de formação católica, da Índia à América do Sul, tomando para si a tarefa da conversão da multiplicidade de povos com os quais os portugueses estabeleciam contatos, o que gerou, por iniciativa de Inácio de Loyola (1491 - 1556), a formulação de um compêndio de regras referentes à forma de funcionamento, ensino e mesmo à definição de autores e conteúdos a serem aplicados universalmente em todas as escolas jesuítas. Este texto normativo recebeu o nome de Ratio Studiorum (Ratio atque Institutio Studiorum) e possui três versões, sendo a última, utilizada nas escolas jesuitas brasileiras até 1759 , quando a ordem é expulsa de Portugal e das suas colônias, iniciativa que se dá no contexto da decadência do movimento escolástico português em sua tentativa de superar o conflito entre fé e razão filosófica, dando então lugar a um direcionamento parcialmente iluminista do pensamento luso, mas que ainda por muito tempo continuou vinculado ao aristotelismo de Coimbra.

A escolástica portuguesa foi um movimento constituído a partir da "união" peninsular, que buscava constituir uma unidade católico-ibérida contrareformista, em oposição ao protestantismo que se ampliava no norte da Europa. Ela representa um pensamento conservador, "com fins explícitos e exclusivamente catequéticos de manutenção e promoção de uma ordem social" (TIMM, 2009, 36), mas com um significativo componente filosófico, que direcionou a ocupação dos jesuítas com a filosofia e às suas formas específicas de delimitações temáticas e metodológicas. A delimitação temática acabou por restringir a reflexão conceitual aos parâmetros da filosofia aristotélica e à interpretação tomista. A metodológica por basear o trabalho filosófico em rigorosas interpretações filológicas dos textos de Aristóteles e de Tomás de Aquino. 
Belém, 2019, V. 1, N.1.

Assim compreendida, a escolástica lusa pode ser entendida como constituída por duas etapas. A primeira, denominada de aristotelismo barroco e caracterizada por um aristotelismo com certa autonomia teórica, mas pautado em grande rigor filológico. Nomes significativos da escolástica barroca portuguesa foram Pedro da Fonseca (1528 - 1599), o “Aristóteles português, Francisco Sanches, Pedro Molina (1535 - 1600), João de Santo Tomás (1589 1644), Francisco Soarez (1548 - 1617)" (MARGUTTI, 2013, p. 62). Em um segundo momento, então sob o domínio espanhol, Portugal assimilou o aristotelismo conservador de Tomás de Aquino, cultivado pelos espanhois, decisivamente o da universidade de Salamanca (MARGUTTI, 2013, p. 61) e voltado à confrontação do movimento reformista e pressupondo uma total submissão da filosofia à teologia.

\section{A modernização conservadora}

Pedro da Fonseca é um nome significativo pelo seu impulso em direção a uma interpretação pós-renascentista rigorosa de Aristóteles. Fonseca tenta uma renovação de Aristóteles. Sua ideia era encontrar uma fundamentação da fé por meio da filosofia do filósofo grego. Visando isto, concebeu a lógica como base analítica possibilitadora da aproximação entre filosofia e fé. Isso o conduziu a uma reflexão sobre a liberdade humana baseada no uso da razão e na atividade, que pressupõe a diferenciação entre determinismo natural e liberdade espiritual, esta última, todavia, baseada no uso correto da razão (ratio formalis) em sentido prático, a qual oferece indicadores significativos de como a filosofia foi mobilizada pelos jesuítas no processo de evangelização em suas escolas. Já no primeiro livro de Pedro da Fonseca, Instituitiones dialeticae (1564) a filosofia aparece caracterizada como omnium scientiarum domina e não como ancilla da teologia, pois segundo ele a lógica aristotélica deveria ser a base de toda investigação intelectiva. Este é um dos pontos que viriam a ser alterados pelos jesuítas de Coimbra em suas inclinações para a escolástica tomista, por conseguinte para a concepção segundo a qual o uso teórico e prático da razão deveriam ser tutelados pela teologia, em um movimento que seria conhecido como “modernização conservadora" (MARGUTTI 2013, p. 64), pois reafirmava em uma nova perspectiva as bases interpretativas, todavia, segundo uma concepção conservadora da religião. No Brasil a tendência escolástica de unir pressupostos filosóficos e atitude prática, marcada por um direcionamento moral da reflexão filosófica, se faz presentes nos pressupostos filosóficos de vários sermões do jesuíta António Vieira (1608 - 1697). Com seus 
Belém, 2019, V. 1, N.1.

sermões, Vieira ofere um quadro imprescindível para a consideração da importância da filosofia grega mobilizada pela igreja católica e pelos interpretes desta no processo de catequisação dos indígenas brasileiros. De platão a agostinho, "o grande santo entre os doutores e o grande doutor entre os santos" (Sermão de Sto. Agostinho, § I), Vieira assimila respectivamente as ideias de autoconhecimento como fundamento da moral e da ação como pressuposto da virtude. Para Vieira, o saber por si mesmo não pode ser sozinho a finalidade da ação humana, mas sim ser compreendido como pressuposto para uma vida virtuosa, que se mostra no resultado do trabalho e das obras. $\mathrm{O}$ aristotelismo de Vieria o leva a relativisar a interioridade como ponto central da formação cristã. Sua teologia e consideração filosófica dos livros bíblicos visam muito mais o pressuposto de uma vida racional, cuja finalidade é a existência ativa entendida como virtuosa segundo os pressupostos católicos.

Ter o nome de pregador, ou ser pregador de nome, não importa nada: as ações, a vida, o exemplo, as obras, são as que convertem o mundo.

Antigamente convertia-se o mundo, hoje porque se não converte mais ninguém? Porque hoje prega-se palavras e pensamentos, antigamente pregava-se palavras e obras. (Sermão da sexagésima, IV)

Para Vieira, o autoconhecimento, incluso o da maldade humana - advinda do corpo -, livra o homem do determinismo da natureza e fundamenta sua existência como ser humano, mas a finalidade do autoconhecimento são as ações morais, que para ele constituem o único caminho para a libertação do sofrimento e da pobreza. $\mathrm{O}$ autoconhecimento deve levar ao domínio de si e à liberdade da vontade ante o mundo e, com isso, alcançar a compreensão da essência da moral, pois o conhecimento só é possível quando o espírito conhece a si mesmo e com isso outros espíritos:

Qual será logo no homem o limpo conhecimento de si mesmo? Digo que conhecer é persuadir-se cada um, que ele é a sua alma. O pó, o lodo, o corpo, não é eu; eu sou a minha alma: este é o verdadeiro, o limpo e o heroico conhecimento de si mesmo; o heróico porque se conhece o homem pela parte mais sublime; o limpo, porque se separar de tudo o que é terra; o verdadeiro, porque ainda que o homem verdadeiramente é composto de corpo e alma, quem se conhece pela parte do corpo, ignora-se, e só quem se conhece pela parte da alma se conhece [...]. Homem, se te ignoras, se te não conheces, sai fora. Eu bem sei que a causa de muitas ignorâncias é o não sair; o homem tanto sabe, quanto sai, e aqueles que não saíram, não sei como podem saber, se não for por ciência infusa, a qual ainda não basta" (VIEIRA, As cinco pedras da funda de Davi, II, p. 532).

O conhecimento objetivo do mundo fica incompleto sem o autoconhecimento e das consequências morais dos atos, trata-se, em Vieira, de uma virtude intelectual com necessário desdobramento prático, que pode ser indicado como um componente central da educação jesuíta, que possibilita a compreensão de seu componente filosófico que se faz presente na Ratio Studiorum. 


\section{A filosofia na Ratio Studiorum}

A Ratio Studiorum espressa o aristotelismo que, sob a ótica da sua aplicação no Brasil, norteava a universidade de Coimbra no século XVI. Não se trata de um texto teórico, o seu conteúdo é decisivamente disciplinar e se refere à ordenação dos estudos nas escolas jesuítas tendo em vista uma formação estreitamente vinculada à formação moral embasada nas virtudes morais do cristianismo católico. O processo de elaboração do documento pode ser compreendido como constituído por três fases, que se inicíam com o envio, sob indicação de Inácio de Loyola, fundador da ordem jesuíta, de Jerônimo Nadal (1507-1580), a diversas escolas, prioritariamente a de Messina e, posteriormente de Roma, tendo em vista o recolhimento de sugestões organizacionais e pedagógicas, o que resultou na primeira versão das regras, em 1552. Esta versão chegou ao Brasil e foi utilizada por mais de três décadas. $\mathrm{O}$ segundo momento é caracterizado pela síntese, feita por Cláudio Acquaviva (1543 - 1615), em 1591, das 837 regras do documento original em 466 regras, ao que se seguiu um período probatório de oito anos até a versão definitiva, em 1599, cuja utilização só seria suspensa em 1759 por determinação do Marquês de Pombal.

Na Ratio Studiorum a filosofia está subordinada e limitada não apenas pela teologia como pela autoridade eclesiástica. A sua função é o "direcionamento do conhecimento do amor do criador e redentor da humanidade" (RS. O objetivo dos estudos da Companhia de Jesus. P. 4 proem. Y c. 12.p. 10, 3). Nela estão indicadas as questões filosóficas que devem ser tratadas pelos estudantes, determinadas tanto no seu grau de importância e atenção, como as que não devem ser tratadas. Na versão de 1599, Filosofia e Teologia encontram-se parcialmente separadas, dadas as especificidades de seus estudos. Para a Teologia é indicada a Summa Teológica de Agostinho, para a Filosofia os textos de Aristóteles, mas de modo limitado. O estudo de filosofia não deveria contradizer os princípios das escolas e universidades. O professor deve buscar "com toda sinceridade e a honra e a glória de Deus" e desse modo, a filosofia deve ser entendida como "preparação para a teologia e exercício para o conhecimento do seu criador" (Fin. P. 4, c. 12,3; y Congr. 3, can. 9, p. 49). Em casos contraditórios, deveria ser observada como autoridade última as palavras contidas no concílio de Latrão (Fin. P. 4, c. 12,3; y Congr. 3, can. 9), que em 1123, em Roma, determinou, dentre outros temas, que a igreja católica era a autoridade máxima com respeito a assuntos espirituais. Um princípio semelhante foi aplicado aos comentadores de filósofos. Eles não deveriam se confrontar com a autoridade religiosa e por isso deveriam ser excluidos dentre 
Belém, 2019, V. 1, N.1.

estes comentadores não cristãos, como Abu al-Walid Muhammad ibn Ahmad ibn Muhammad ibn Rushd ou Averróis (1126 - 1198).

O estudo de filosofia deveria durar três anos, um ano a menos que o estudo de Teologia. O primeiro ano seria dedicado ao estudo da lógica, segundo o livro de Toledo e Fonseca, baseado na lógica de Aristóteles. Os escritos do estagirita também deveriam ser analisados, de modo que os primeiros conceitos da metafísica e da física fossem transmitidos. No segundo ano o tema seria a física, segundo os textos De coelo e De generatione et corruptione de Aristóteles. O terceiro ano deveria ser dedicado ao estudo da metafísica, segundo o De Anima e Metafísica, com un direcionamento para a filosofia moral, cujos textos centrais também deveriam ser de Aristóteles (Oficio. P. 4, c. 14,3.1).

Analisada a ordenação do uso da filosofia na Ratio, fica claro o significado da recuperação da importância da filosofia aristotélica para a educação sob a ótica dos jesuítas. Trata-se de uma tendência que começa em París, em 1366, quando a igreja determinou a leitura dos textos do estagirita como pressuposto para a aprovação de estudantes de Artes junto a universidade daquela cidade. Aristóteles, porém, estivera proibido desde 1211, sob acusação de heresia de sua Física, o que, porém, não impediu, mas arrefeceu sobremaneira a leitura pública de suas obras. Apenas no início da modernidade esta proibição foi suspensa, motivada precisamente por uma perspectiva prática da reflexão filosófica a serviço da fé e, a partir de então, ela foi significativamente adequada aos interesses da formação da Companhia de Jesus e da Igreja Católica.

\section{A expulsão dos jesuítas e as suas consequências para o ensino da filosofia no Brasil}

Não seria possível aqui abordar todos os aspectos relativos à tensão entre a Companhia de Jesus e a Coroa Portuguesa, que culminou com a expulsão por meio do Alvará Régio do Marquês de Pombal, em 28 de junho de 1759, dos padres jesuítas do Brasil. Neste sentido, um ponto de partida seguro é compreender a tensão no século XVIII entre as visões naturalista e iluminista com a aristotélica e mediaval dos jesuítas. Um dos efeitos da reforma protestante, mesmo que não planejado, foi a restrição de âmbitos de atuação e controle da igreja católica dos centros de formação e investigação na europa, criando possibilidades de investigação que até então sofriam severo controle da igreja romana. Cada vez mais ficava evidente para a Coroa portuguesa o descompasso entre os avanços científicos e técnicos de outros países europeus concorrentes e o estágio portugês. O século XVI já havia iniciado uma reflexão e 
Belém, 2019, V. 1, N.1.

tomadas de atitude outra com respeito à relação entre homem e natureza e, por exemplo, com Francis Bacon, feito não apenas uma crítica do controle religioso-institucional da investigação natural, como indicado mudanças metodológicas com vistas a maximizar os esforços humanos de compreensão e utilização das potencialidades naturais. O impacto desta perspectiva no que se refere à exploração dos territórios conquistados pelas nações expansionistas européias não pode ser menosprezado. Ela começa nos países colonizadores com significativas reformas nos processos de capacitação da força colonizadora, em uma ampla mudança que envolvia pressupostos militares, administrativos e científicos.

Sebastião José de Carvalho e Melo, o marquês de Pombal, fora diplomata português em Londres em 1738 e em Viena, em 1745, sob o reinado de Don João V. Nestes dois momentos teve oportunidades de ter contato direto com ideias iluministas o que o levou, enquanto primeiro ministro de D. José I - filho e sucessor de D. João V - e após sua importante atuação na reorganização de Lisboa após o terremoto de 1755, a emprennder significativas reformas administrativas e educacionais que se confrontavam diretamente com a perspectiva dos jesuítas estabelecida tanto em Portugal como no Brasil.

Mesmo convicto da superioridade da visão objetivante e universalista do iluminismo, baseada em um modelo geométrico dedutivo, Pombal não deve ser diretamente considerado como um entusiasta político das ideias iluministas. Neste sentido ele permaneceu sempre um monarquista absolutista, mas que objetivava racionalizar a administração das colônias, adequando-as a um projeto de modernização de Portugal. Este projeto, pensado no contexto do absolutismo monarquico português, entrou em conflito direto com a hegemonia dos jesuítas no contexto educacional (WOOLLEY, 2009, p. 5), tanto no seu país, quanto nas colônias. Enquanto a educação jesuítica acalentava um forte componente individual, expresso na ideia de uma mudança interior do convertido, a perspectiva pombalina partia da objetivação de modelos racionais, marcados por pragmáticas temáticas. A resistência dos jesuítas a este modelo, foram interpretadas como uma ingerência da Companhia de Jesus nos negócios da Coroa, o que motivou o acirramento das relações entre Igreja e Estado. A atuação jesuítica nas escolas foi questionada tanto a partir de conteúdos como de metodologias, mas tendo como pano de fundo central a sua significação política.

Dentre as muitas reformas que empreendeu a partir de sua nomeação como primeiro ministro, Pombal realizou uma reforma estrutural do ensino, tanto das escolas como das universidades portuguesas. Através do Alvará Régio Pombal suprimiu as escolas jesuíticas de Portugal e de todas as colônias e expulsou os jesuítas de todos os domínios lusos. Ao mesmo 
Belém, 2019, V. 1, N.1.

tempo, reconfigurou os cursos, reformulando os existentes de Gramática, Latim, Grego e Retórica, que deveriam substituir os conteúdos ministrados nas escolas jesuítas, buscando laicizar o ensino.

A reforma pombalina foi primeiramente pensada tendo em vista a formação de uma elite intelectual portuguesa capaz de promover o desenvolvimento do Estado português enquanto poder colonial ${ }^{2}$. Ela não foi concebida inserindo as colônias no âmbito desta problematização, tendo sido o efeito da mesma bastante negativo no caso brasileiro, onde o sistema de ensino foi completamente desestruturado, sem que houvesse uma alternativa eficiente para substituir a educação promovida pelos jesuítas. Fechadas as escolas jesuítas, restaram então a uma minoria de brasileiros as aulas régias, aulas de disciplinas isoladas, na maioria dos casos ministradas por mestres de qualidade contestável.

No Alvará Régio a filosofia não é mencionada, certamente por conta não apenas de seu vínculo com a Companhia de Jesus, mas também pela valorização de uma educação humanista mais ampla que certamente não a excluía, mas que priorizava uma perspectiva naturalista segundo a qual a filosofia teria uma função propedêutica (QUILLICI, 2007, p. 32). $\mathrm{O}$ aristotelismo dos jesuítas, todavia, jamais foi superado (Idem, p. 35). Mesmo tendo sido proibidas considerações públicas a seu respeito, após a suspensão desta em 1780 por D. João VI, em uma série de aulas sobre física experimental no Palácio das Necessidades em Lisboa ela voltou a ser mencionada, o que indica a permanência da manutenção do desejo de intelectuais ligados à igreja de empreender uma adequação do aristotelismo conimbrisense à atualidade. Esta tendência se confirma quatro anos depois, também em Lisboa, quando o padre João Batista apela, em uma série de conferências acerca da filosofia do estagirita, para uma possivel renovação da sua filosofia. Os temas destas conferências mostram um aspecto central da retomada filosófica em terras portuguesas, ela ainda se pautava na sua dependência da filosofia aristotélica, dos jesuítas, todavia em um período de afastamento com respeito a ela.

No Brasil o mesmo caso ocorre, porém com anos de atraso. A filosofia é permitida publicamente apenas em 1813, Rio de Janeiro, já capital do país e com um curso sobre a

\footnotetext{
${ }^{2}$ Ou como consta no Alvará: "Eu ELREY. Faço saber aos que este Alvará virem, que tendo consideração a que da cultura das Sciencias depende a felicidade das Monarquias, conservando-se por meio dellas a Religião, e a Justiça na sua pureza, e igualdade; e a que por esta razão forão sempre as mesmas Sciencias o objeto mais digno do cuidado dos Senhores Reys meus Predecessores, que com as suas Reaes Providencias estabelecerão, e animarão os Estudos públicos; promulgando as Leys mais justas, e proporcionadas para que os Vassallos da minha Coroa pudessem fazer á sombra dellas os maiores progressos em benefício da Igreja, e da Pátria”. Conf. http://www.unicamp.br/iel/memoria/crono/acervo/tx13.html.
} 
Belém, 2019, V. 1, N.1.

retórica aristotélica, proferida pelo português Silvestre Pinheiro Ferreira (1769-1846) e, com a manuência do imperador, novamente repetidas em 1816. O curso de Ferreira expressa o "empirismo moderado" (PAIM, 2007, S. 21), que posteriormente resultaria no ecletismo, que também pode ser entendido como uma série de adaptações do aristotelismo jamais superado ante a ascensão do empirismo e do naturalismo.

\section{Considerações Finais}

A argumentação precedente buscou de forma elementar abordar aspectos imprescindíveis à compreensão da chegada da filosofia no Brasil e de sua recepção inicial, marcada pela interpretação e uso religioso da filosofia aristotélica que marcou a passagem da escolástica barroca para a tomista, aprofundando ainda mais em Portugal o rigor exegético no estudo da filosofia do estagirita. O ápice deste processo foram os Cursus Conimbricensis, com grande profundidade interpretativa das obras de Aristóteles, que então entra em decadência a partir da segunda metade do século XVII (CERQUEIRA, 2009, 163) ante a ascensão do naturalismo e das ciências naturais. A reflexão filosófica iniciada no Brasil no século XIX não pode ser coerentemente compreendida sem que se abarque também as suas recepção e assimilação de uma tentativa de reforma e adequação do aristotelismo que acompanharia o pensamento português por várias décadas, mesmo depois da reforma pombalina e do "empirismo mitigado" de Luís António Verney (1715-1792) e do direcionamento ao pensamento francês de Domingos José Gonçalves de Magalhães (18111882) os quais, todavia, não podem ser discutidos aqui. Mesmo passados mais de dois séculos da reforma de Pombal, a pesquisa filosófica no Brasil ainda mantém, dentre outras coisas, um forte viés filológico, baseado na leitura exegética minuciosa de textos de autores, ou modelos filosóficos já constituídos (SEVERINO, 1997, p. 24), enquanto critério de validade do estudo filosófico. Do mesmo modo, a crítica de um suposto reducionismo materialista das ciências, confrontadas com a especulação acerca de dimensões não sensíveis ou mensuráveis, que claramente podem ser remetidas à separação entre corpo e alma do tomismo barroco e que mobilizaria a oposição em terras brasileiras entre positivistas e espiritualistas ecléticos, alcançando mesmo a reflexão de membros da assim chamada "Escola do Recife", como Tobias Barreto (1839 - 1889) e Farias Brito (1862 - 1917). É a percepção crítica da vinculação histórica entre religião e pensamento filosófico que leva a Sylvio Romero (1815 1914), também membro da supracitada “escola”, nas palavras iniciais de seu ensaio crítico $A$ 
Belém, 2019, V. 1, N.1.

filosofia no Brasil, publicado em 1872, a escrever: "Pode-se afirmar, em virtude da indagação histórica, que a filosofia, nos três primeiros séculos da nossa existência, nos foi totalmente estranha" (ROMERO, 1969, § I, p. 7). Não se trata aqui de dar razão a Romero, mas de indicar aspectos imprescindíveis para a consideração da reflexão filosófica no Brasil e que constitui um campo de pesquisa ainda bastante reduzido para a importância que comporta ${ }^{3}$.

\section{REFERÊNCIAS BIBLIOGRÁFICAS}

BARRETO, Tobias. Estudos de filosofia. São Paulo: Grijalbo, 1977.

CERQUEIRA, Luiz Alberto. A projeção do aristotelismo português no Brasil. In Luis Alberto Cerqueira (Org). Aristotelismo e Antiaristotelismo: Ensino de Filosofia. Rio de Janeiro: Editora Ágora da ilha, 2000, p. 217 - 234.

A ideia da Filosofia no Brasil. Coimbra: Revista filosófica de

Coimbra, n. 39, 2001, p. $163-192$.

COXITO, Amandio, A. Aristotelismo e antiaristotelismo no pensamento português dos séculos XVI a XVIII. In Luis Alberto Cerqueira (Org). Aristotelismo e Antiaristotelismo: Ensino de Filosofia. Rio de Janeiro: Editora Ágora da ilha, 2000,, p. 161 - 178.

MACHADO, Geraldo Pinheiro. A Filosofia no Brasil. São Paulo: Cortez e Morais, 1976.

MARGUTTI, Paulo. História da filosofia no Brasil. O período colonial (1500 - 1822). São Paulo: Ed. Loyola, 2013.

PAIM, Antonio. O estudo do pensamento filosófico brasileiro. São Paulo: Ed. Convívio, 1986.

A Escola eclética. Estudos complementares aos estudos das ideias filosóficas no Brasil. Londrina: Edições CEFIL, 1999.

Ciclos da escola do recife.

http://www.cdpb.org.br/os_ciclos_da_escola_do_recife.pdf.

\footnotetext{
${ }^{3}$ Passos nesta direção já foram dados, tal como o aumento de publicações sobre o tema na última década, mas, decisivamente, com a criação do Centro de Filosofia Brasileira, coordenado pelo Professor do Programa de PósGraduação da Universidade Federal do Rio de Janeiro (UFRJ), Dr. Luiz Alberto Cerqueira e que mantém uma imprescindível fonte de material de pesquisa acerca deste domínio de estudos em: http://textosdefilosofiabrasileira.blogspot.com.
} 
Belém, 2019, V. 1, N.1.

. História das idéias filosóficas no Brasil. Band I. 6 Auflade. Rio de janeiro:

Edições humanidades, 2007.

. A Filosofia brasileira. Ratio Studiorum. Rio de janeiro: Agir, 1952.

MAGAlHÃeS, D. J. G. Factos do espírito humano. Paris: Na livraria D’auguste Fontaine, 1858.

MARTINS, António Manoel. Conimbrigensis. Introductory not to the Comentarii collegii conimbricensis societatis jesu. Biblioteca SAAVEDRA FAJARDO do pensamento Político hispânico.

. A recepção da metafísica de Aristóteles na segunda metade do sec.

XVI. In Luis Alberto Cerqueira (Org,). Aristotelismo e Antiaristotelismo: Ensino de Filosofia. Rio de Janeiro: Editora Ágora da ilha, 2000, p. 93 - 110.

QUILLICI, Neto, Armindo. O ensino da filosofia no Período da reforma pombalina e suas conseqüências na formação cultural do homem brasileiro: breve reflexão. Revista HISTEDBR On-line, Campinas, n.27, p.29 -37, set. 2007 - ISSN: 1676-2584. Disponível em: http://www.histedbr.fe.unicamp.br/revista/edicoes/27/art03_27.pdf. Acessado em: 13.07.2018.

RODRIGUES, Teresa F. A população portuguesa. Das longas permanências à conquista da modernidade. Porto: CEPESE, Vol, 18, 2010, p. 21 - 41.

ROMERO, Sylvio. Obra filosófica. Rio de janeiro: José Olímpio, 1969.

SEVERINO, Antonio Joaquim. A filosofia contemporânea no Brasil. Petrópolis: Editora vozes, 2001.

SOUZA, Ricardo Timm. O Brasil filosófico. História e sentidos. São Paulo: Editora Perspectiva, 2009.

VIEIRA, António. Sermões. Porto: Lello \& Irmãos, 1959, 15 tomos, 5 vols. Sermões. Organização de Alcir Pécora. São Paulo: Hedra, 2000-2001, 2 vols.

POMBAL, Marquês. Alvará Régio. Disponível em:: http://www.unicamp.br/iel/memoria/crono/acervo/tx13.html. Acesso em: 05.2013. 
REVISTA APOENA - Per. dos Dis. de Fil. da UFPA

Belém, 2019, V. 1, N.1.

WOOLLEY, Patrícia Domingos. Os jesuítas no setecentos europeu: autoridade, ensino e poder. In: Revista Cantareira, 6 ${ }^{\mathrm{a}} \mathrm{ed}$ on-line, 2009. Disponível em: < http://www.historia.uff.br/cantareira/novacantareira/index.php?option=com_content\&v ew=article \&id=129:osjesuitasnosetecentos-ed6\&catid=61:artigos-ed6\&Itemid=79>. Acesso em jul./2017. 